\title{
Neutrophil-lymphocyte and platelet-lymphocyte rate and their seasonal differences in ankylosing spondylitis and rheumatoid arthritis patients using anti-TNF medication
}

\author{
Enginar AU, Kacar C \\ Akdeniz University, Medicine School, Physical Therapy and Rehabilitation, Rheumatology, Antalya, Turkey. \\ ftrdrayseenginarvgmail.com
}

\begin{abstract}
OBJECTIVE: In recent years, neutrophil-lymphocyte rate (NLR) and platelet-lymphocyte rate (PLR) are reported to be increasing in plenty of rheumatological diseases and the latter rates to be disease activity indicators. In our study, we aimed to search for the difference in NLR and PLR before and after the treatment, their relationship with the disease activity and their seasonal differences in patients using anti-TNF medication for rheumatoid arthritis (RA) and ankylosing spondylitis (AS) while.

METHOD: Sixty-eight RA and 203 AS patients using anti-TNF medication for at least 6 months were included in the study. Patients with acute infection, diabetes, hypertension, cancer, renal failure and liver failure were excluded from the study. NLR, PLR, seasonal differences and the disease activities of the patients were evaluated retrospectively.

RESULTS: We determined that NLR and PLR are strongly correlated with disease activity, erythrocyte sedimentation rate (ESR) and c-reactive protein (CRP). In addition, we determined that disease activity, thrombocytes and PLR are increased in spring and winter, especially in patients with RA.

CONCLUSION: NLR and PLR are simple, cheap, and easily accessible parameters which can be used to evaluate disease activity and treatment response before and after anti-TNF treatment. Further studies are needed to enlighten the effect of seasonal differences on disease activity (Tab. 2, Fig. 2, Ref. 43). Text in PDF www.elis.sk. KEY WORDS: neutrophil, lymphocyte, platelet, rate.
\end{abstract}

\section{Introduction}

Rheumatoid arthritis (RA) and ankylosing spondylitis (AS) are chronic inflammatory diseases with unknown etiology. The disease activity is currently evaluated with clinical symptoms, laboratory tests and some clinical scales. To establish the disease activity, the Bath Ankylosing Spondylitis Disease Activity Index (BASDAI) is used for AS, and DAS 28 (Disease Activity Score) is frequently used for RA. Erythrocyte sedimentation rate (ESR) and C-reactive protein (CRP) are the most frequently used laboratory workups.

Complete blood count parameters, especially neutrophils, lymphocytes and platelets, which are part of the immune system, play important roles in evaluating various diseases and controlling inflammation (1). In recent years, the neutrophil-lymphocyte ratio (NLR) and platelet-lymphocyte ratio (PLR) have been shown to be markers of systemic inflammation associated with the prognosis of numerous cardiovascular diseases, malignancies and chronic

Akdeniz University, Medicine School, Physical Therapy and Rehabilitation, Rheumatology, Antalya, Turkey

Address for correspondence: Dr. A. Unal, Akdeniz University, Medicine School, Physical Therapy and Rehabilitation, Rheumatology, Antalya, Turkey.

Phone: +02422496675-05327239988 inflammatory diseases. In addition, NLR and PLR have an established relationship with erythrocyte sedimentation rate (ESR), Creactive protein (CRP) and interleukin-6 (IL-6), and tumor necrosis factor-alpha (TNF $\alpha)(2-5)$. Increased neutrophil count and decreased lymphocyte count were reported to be independent predictors for mortality in the Baltimore Longitudinal Study of Aging (6).

Furthermore, the existence of seasonal patterns such as seasonal lability of the effect (7), arthritis (8), blood pressure (9), and cardiovascular and respiratory mortality and morbidity (10-13) have been long known. The cellular and molecular mechanisms of the effect of seasonal differences are not fully understood, and new studies have shown that the gene expressions of biomarkers of leukocytes, fat tissue and inflammatory immune system are periodical (14-16). A seasonal difference is found in blood cell distribution and inflammatory biomarkers such as CRP. Mortality and morbidity are more common in cold seasons (8-19).

The aim of this study was to investigate the differences in complete blood count parameters before and after treatment and their seasonal relationships in RA and AS patients using anti-TNF.

\section{Materials and methods}

The study included 68 patients diagnosed with RA according to the 1987 ACR criteria and 203 patients diagnosed with AS 
according to the modified New York criteria, who had follow-up examination data in the hospital information system in Akdeniz University Department of Physical Therapy and Rehabilitation, Rheumatology Polyclinics between 2014 and2017. Patients who had been using anti-TNF drugs for at least for 6 months were included in the study. Patients with acute infection, diabetes, hypertension, cancer, renal failure and liver failure were excluded from the study.

The data related to the date of presentation at the clinic were obtained from the hospital information system and statistically analyzed. Namely age, gender, duration of disease, medications used. ESR, CRP, and complete blood count parameters were obtained from all patients, while rheumatoid factor (RF), anti-cyclic citrullinated peptide (anti-CCP) and DAS 28 was analyzed for RA patients, whereas HLA-B27 and BASDAI were evaluated for AS patients for all patients. Hemoglobin (hgb), hematocrit (htc), erythrocytes (RBC), leukocytes, neutrophils, lymphocytes, platelets, RDW, MCV, and MPV were taken as complete blood count parameters. NLR was calculated by dividing the neutrophil count by lymphocyte count, while PLR was determined by dividing the thrombocyte count by lymphocyte count. Complete blood count parameters, DAS 28, BASDAI, ESR, and CRP values were obtained before starting anti-TNF treatment, and 3 and 6 months thereafter. In addition, the dates of obtaining the latter parameters were recorded and used for the analysis of their seasonal variability parameters.

The approval for the study was granted by the Ethics Committee of Akdeniz University Medical School.

\section{Statistical analyses}

The statistical analyses were performed using commercially available software SAS, version 9.4 (SAS Institute, Cary, NC, USA). Descriptive statistics such as the mean and standard deviation, were used to describe the main variables. The Shapiro-Wilks normality test was conducted to assess the normality of variables to determine the use of parametric or non-parametric tests. Since all variables were not normally distributed, the non-parametric Mann-Whitney U-test and Kruskal-Wallis test were used to determine possible differences in variables of interest between the groups. A two-sided probability value of $<0.05$ was considered to be statistically significant for all analyses.

\section{Results}

The laboratory results of 68 RA and 203 AS patients included in the study were evaluated retrospectively. The patients' demographic features, DAS 28, BASDAI, ESR, CRP and complete blood count parameters are shown in Table 1.

The RA group of 68 patients comprised 52 females (76.4\%) and 16 males $(23.6 \%)$ with mean age of $52 \pm 13.2$ years. The AS group of 203 patients comprised 39 females (19.2\%), and 164 males $(80.8 \%)$ with mean age of $39.4 \pm 10.74$ years. The mean duration of disease was $13.2 \pm 8.89$ years in RA group, and 11.8 \pm 7.72 years in AS group. Of the RA patients, 57 had anti-CCP results, of whom 29 (50.8\%) were positive. Sixty-four patients had RF results, of whom 31 (48.4\%) were positive. Of the HLA B27 results from $30 \mathrm{AS}$ patients registered in the hospital information system, 22 (73.3\%) were positive. The anti-TNF medications which the patients used and their rates in RA and AS were etanercept $39(57.3 \%), 89(43.8 \%)$, infliximab 7 (10.2\%), 54 (26.6 $\%$ ), adalimumab $18(26.4 \%), 42$ (20.6\%), golimumab 2 (2.9\%), $16(7.8 \%)$, and certolizumab $2(2.9 \%), 2$ (0.9\%), respectively.

The laboratory values before anti-TNF treatment and at 3 and 6 months into the latter treatment are shown in Table 2.

In RA patients, DAS 28, NLR and PLR measured at 3 and 6 months after the treatment were statistically significantly lower than in pre-treatment measurements (p: $0.000-0.004-0.01$ ). ESR and CRP were also significantly lower than pre-treatment measurements (p: 0.03). There were no statistical differences in other parameters $(\mathrm{p}>0.05)$. No statistically significant differences in NLR and PLR were determined between values taken 3 and 6 months after the initiation of treatment. At all the time points, there was a statistically significant difference between DAS 28 , ESR and CRP.

The BASDAI, ESR, CRP, leukocyte, neutrophil, platelet, NLR, and PLR values measured 3 and 6 months into the treatment were statistically significantly lower than pretreatment values before in AS patients $(\mathrm{p}<0.001)$. There was a statistically significant difference between the 3 and 6-month values of BASDAI, ESR and CRP. Hgb, Htc and lymphocyte levels were also statistically significantly higher than before the treatment (p: $0.000-0.003-$ 0.006 ). When pre-treatment values, posttreatment values and those measured 3 and 6 months into the treatment were compared, there were no statistically significant differences in respect of RBC, MCV, RDW, and MPV values ( $\mathrm{p}>0.05$ ).

NLR and PLR showed no correlation with age or duration of diagnosis. A statistically significant relationship was found between NLR and PLR and ESR, CRP, BASDAI, and DAS 28. There was no correlation between CRP and DAS 28 in RA patients. A sig-

Tab. 1. The patients' demographic features, DAS 28, BASDAI, ESR, CRP and complete blood count parameters.

\begin{tabular}{|c|c|c|c|c|c|c|}
\hline & & RA & & & AS & \\
\hline & $\mathrm{N}$ & mean & $\begin{array}{c}\text { Std } \\
\text { deviation }\end{array}$ & $\mathrm{N}$ & mean & $\begin{array}{c}\text { Std } \\
\text { deviation }\end{array}$ \\
\hline age & 68 & 52.01 & 13.24 & 203 & 39.41 & 10.74 \\
\hline Duration disease & 68 & 13.25 & 8.89 & 203 & 11.81 & 7.72 \\
\hline anticcp & 28 & 134.61 & 99.67 & & . & . \\
\hline $\mathrm{rf}$ & 31 & 203.48 & 221.62 & & . & . \\
\hline $\begin{array}{l}\text { das28 } \\
0 . \text { month }\end{array}$ & 68 & 6.28 & 0.77 & & . & . \\
\hline $\begin{array}{l}\text { das28 } \\
\text { 3.month }\end{array}$ & 68 & 4.26 & 1.15 & & . & . \\
\hline $\begin{array}{l}\text { das28 } \\
\text { 6.month }\end{array}$ & 68 & 2.96 & 1.31 & & . & . \\
\hline $\begin{array}{l}\text { basda1 } \\
\text { 0.month }\end{array}$ & & . & . & 202 & 6.68 & 0.92 \\
\hline $\begin{array}{l}\text { basda1 } \\
\text { 3.month }\end{array}$ & & . & . & 202 & 3.73 & 1.37 \\
\hline $\begin{array}{l}\text { basda1 } \\
6 . \text { month }\end{array}$ & & . & . & 202 & 2.26 & 1.36 \\
\hline
\end{tabular}


Tab. 2. The laboratory values before anti-TNF treatment and at 3 and 6 months into the latter treatment.

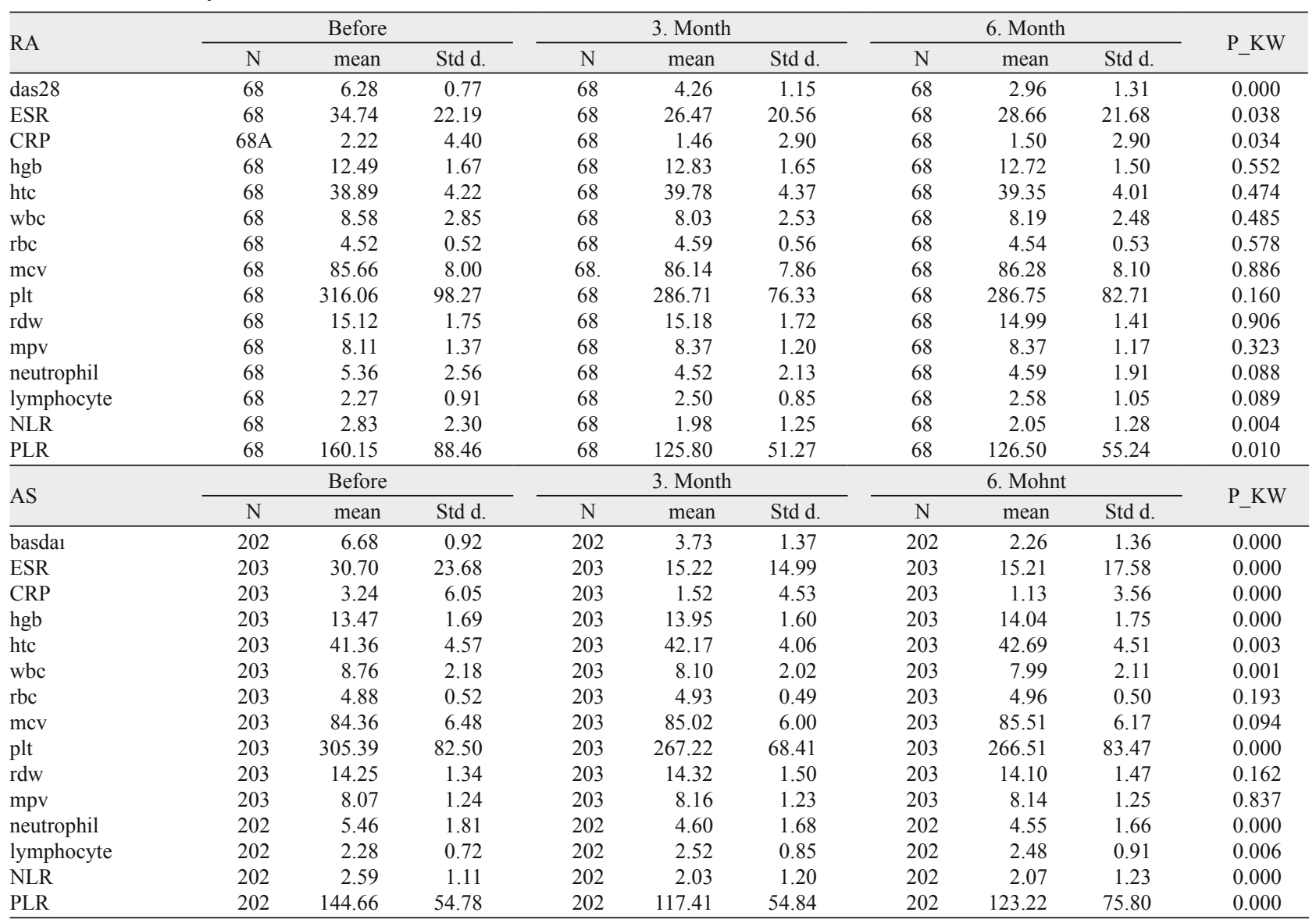

nificantly stronger correlation was found between NLR and PLR and BASDAI than with DAS $28(\mathrm{p}<0.001)$.

In RA patients, NLR was correlated with DAS 28, ESR, CRP, counts of leukocytes, neutrophils lymphocytes, and thrombocytes, and MPV,; PLR was correlated with DAS 28, ESR, CRP, hgb, htc, RDW, MPV and thrombocyte, neutrophil and lymphocyte counts (Fig. 1).

In AS patients, NLR and PLR were correlated with duration of diagnosis, BASDAI, ESR, CRP, hgb, leukocyte, neutrophil, lymphocyte and thrombocyte counts MCV, , and MPV,. Differently from NLR, PLR was correlated with hgb and RBC count (Fig. 2).

When viewed seasonally, DAS 28, platelet and PLR were statistically significant in RA patients (p: $0.000-0.034-0.027$ ). DAS 28 was higher in spring and winter, and lowest in fall. Platelet and PLR were highest in winter and lowest in summer.

The only seasonally statistically significant parameter was RBC count in AS patients (p: 0.03), which was detected to be higher in winter.

\section{Discussion}

Acute phase response scales are used for rheumatological diseases such as RA and AS. DAS 28 is used for RA, and BASDAI for AS in follow-ups and evaluation of treatment responses. Nevertheless, these scales can be insufficient in showing disease activity. ESR and CRP can be found to be normal even when there are clinical findings of the disease. Therefore, some practical, cheap, easily accessible and repeatable tests have come into use for the evaluation of inflammation. In many recent studies of NLR and PLR, both of these ratios have been found to be elevated in inflammatory diseases, malignancies and cardiovascular diseases.

Although DAS 28, ESR, CRP, NLR and PLR in the current study were significantly higher before anti-TNF treatment in RA patients, they decreased significantly after the treatment. In a study of 128 RA patients, Fu et al. showed that NLR and PLR were correlated with DAS 28 and these scales could be used to evaluate the disease activity in RA patients. Correlations of NLR with ESR and CRP, and PLR with CRP were detected (20). Uslu et al. found significantly high NLR and PLR values in RA patients and detected a positive correlation between DAS 28 and NLR, and PLR (1).

In the current study, post-treatment values in AS patients, namely those of BASDAI, ESR, CRP, counts of leukocytes, neutrophils, and platelets, NLR, and PLR were statistically significantly lower than their pre-treatment values. Hgb, htc and lymphocyte levels were statistically significantly higher than in pre-treatment measurements. Gökmen et al found NLR in AS to be higher than 

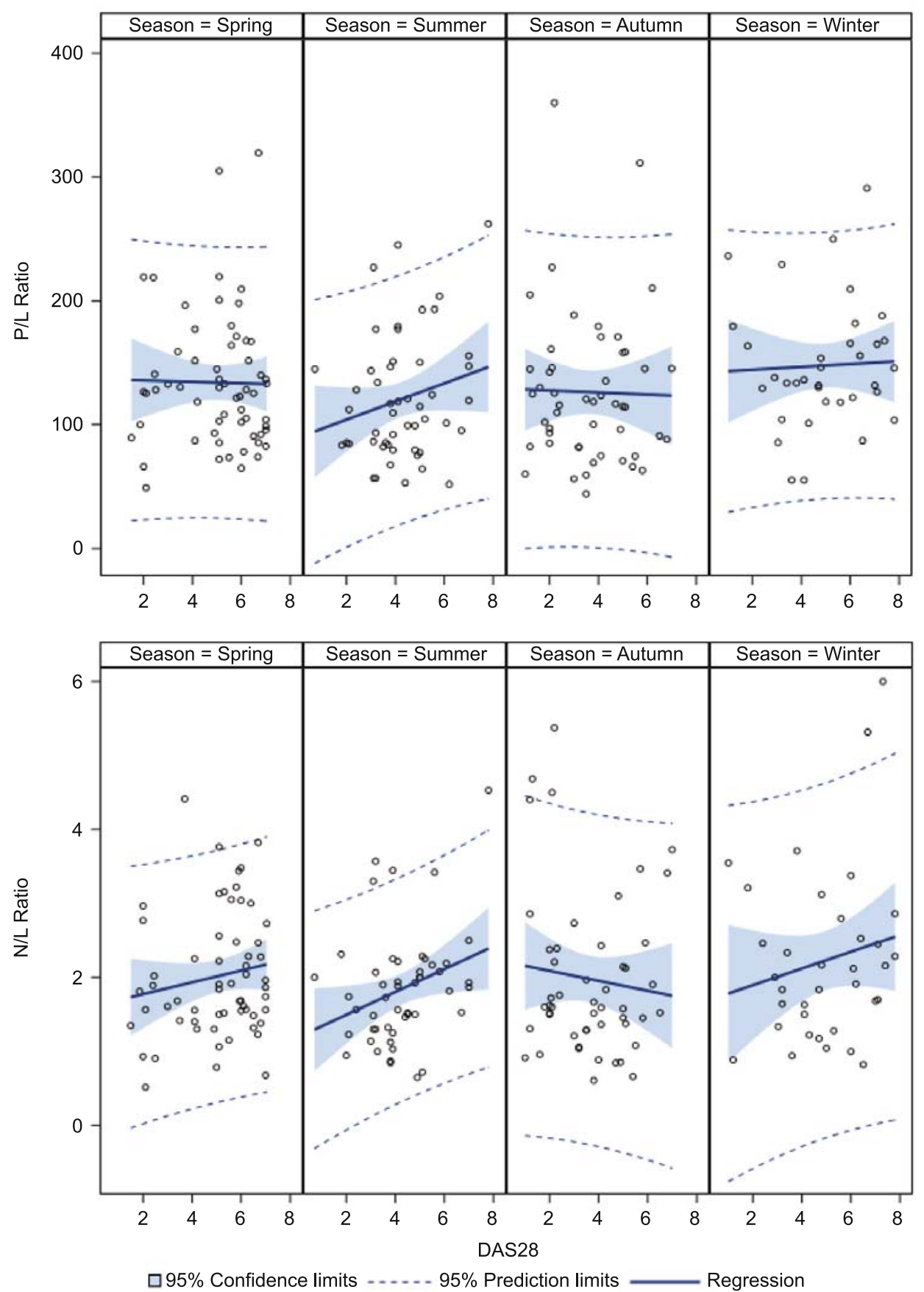

Fig. 1. In RA patients, NLR was correlated with DAS 28, ESR, CRP, counts of leukocytes, neutrophils lymphocytes, and thrombocytes, and MPV,; PLR was correlated with DAS 28, ESR, CRP, hgb, htc, RDW, MPV and thrombocyte, neutrophil and lymphocyte counts.

in the control group. It was reported that NLR was lower in AS patients receiving anti-TNF treatment than in patients receiving non-steroidal anti-inflammatory drug treatment and it was correlated with CRP (21). Coşkun et al reported higher NLR levels in AS patients than in the control group and observed that they decreased significantly with anti-TNF treatment. NLR was also determined to be correlated with ESR, CRP and BASDAI (22).
Boyraz et al found no significant difference in NLR between AS patients receiving anti-TNF treatment and a healthy control group and PLR was determined to be significantly lower in the patients than in the control group (23). Mercan et al reported higher NLR values in RA and AS patients than in the control group, with a correlation between ESR, CRP and DAS 28, but no relationship was determined with BASDAI (24). 

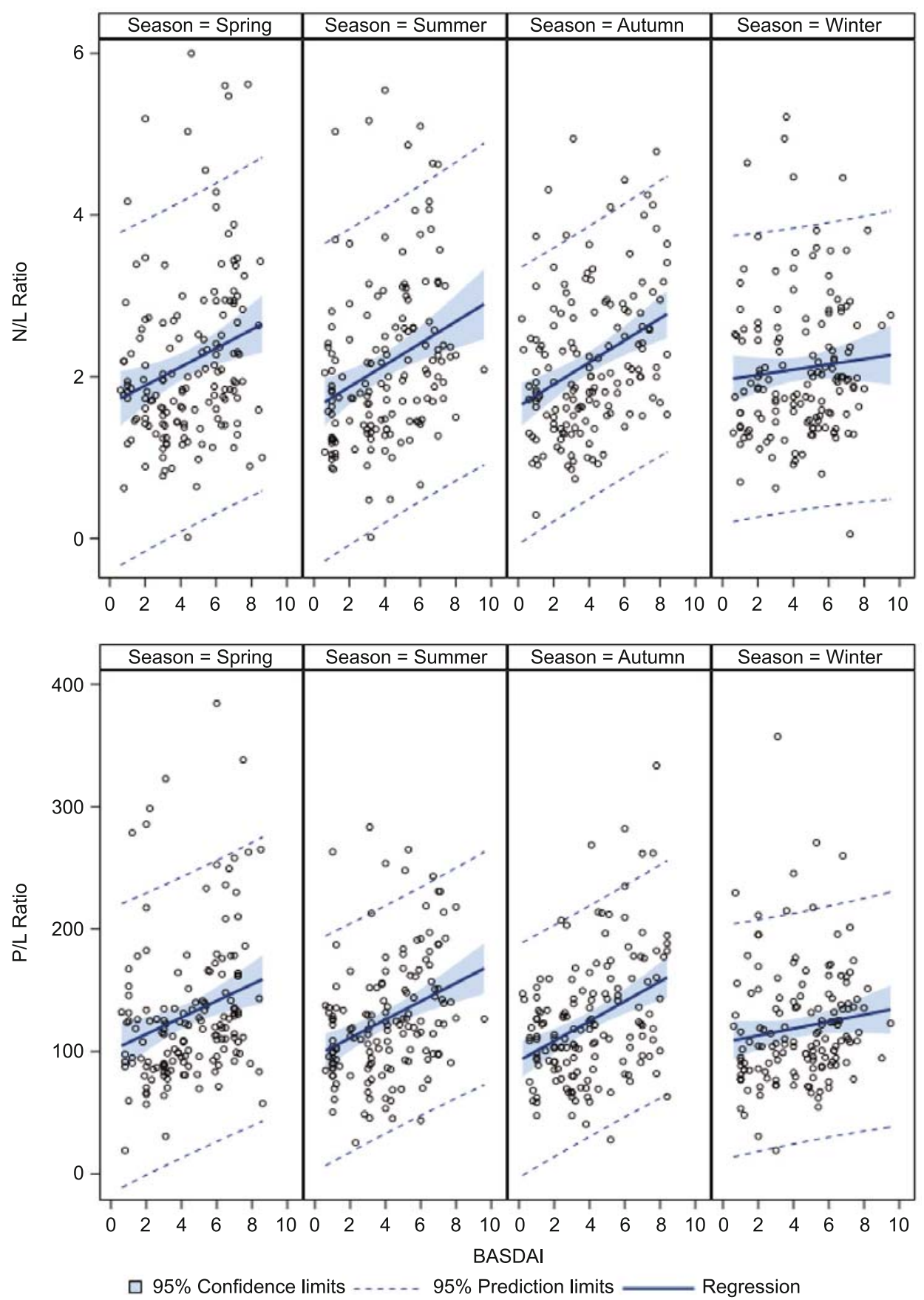

Fig. 2. In AS patients, NLR and PLR were correlated with duration of diagnosis, BASDAI, ESR, CRP, hgb, leukocyte, neutrophil, lymphocyte and thrombocyte counts MCV, , and MPV,. Differently from NLR, PLR was correlated with hgb and RBC count.

In inflammation, an increase in the thrombocyte count is a sign of acute phase response. Thrombocytes play an important role in inflammation, namely inreleasing proinflammatory cytokines and causing leukocyte migration, which then bind to the endothelial cells. A correlation has been proven between MPV, thrombocyte function and activation $(25,26)$. Megakaryopoiesis is affected with the effect of proinflammatory cytokines on bone marrow and this can cause the thrombocyte volume to decrease (26). Kapsoritakis et al found the MPV level to be significantly lower in inflammatory bowel disease than in the healthy group (27). Kisacik et al reported significantly lower MPV levels in RA and AS patients than in the healthy group and they determined that MPV was elevated after treatment (28). In a study of RA patients receiving anti-TNF treatment for 3 months, Gasparyan et al detected that DAS 28 and 
thrombocyte levels decreased and MPV increased significantly over the 3 months (29). Yazici et al detected a positive correlation between DAS 28 and MPV in RA patients (30). In the current study, it was determined that in RA and AS patients, the thrombocyte count decreased and MPV increased after treatment, but in AS patients only the decreased thrombocyte count was statistically significant.

There are known to be seasonal patterns in some diseases (7-13). In clinical practice, RA patients frequently state that their joint pain and stiffness are increased in cold and rainy weather. Few studies have researched the connection between RA and weather conditions, and most have been focused on temperature and humidity. In one study, as a result of evaluating 133 RA patients receiving anti-TNF treatment, it was detected that the disease activity was lower in sunny and less humid weather (31). Abasolo et al previously reported that RA worsened in low temperatures in middle-aged (50-65 years) patients (32). Strusberg et al detected a significant correlation between low temperature, high atmospheric pressure, high humidity, and pain in RA (33). The onset of RA is usually in winter. In epidemiological studies made in the northern hemisphere, the onset of RA has been reported to increase two-fold in the months between October and March $(34,35)$. It is accepted that there are changes in the activity and severity of RA according to the regional and climate differences (36). Recent studies have shown that the onset or exacerbation of autoimmune diseases such as RA and SLE can be associated with seasonality (37). According to some authors, RA starts suddenly in spring, and insidiously in fall, with equal ratios in summer and winter (38). The classical opinion in RA is that cold and humid weather is bad, whereas hot and dry weather is good. It is striking that in all the studies made in respect of humidity and RA variables, no negative correlation has been determined. A positive relationship has been shown in 10 out of 16 studies (39). Çay et al recruited 56 patients diagnosed with RA, spondyloarthropathy and osteoarthritis in a study and detected that the changes in weather condition had a 17.1 $\%$ effect on rheumatismal symptoms. Although not of a statistically significant level, it could not be fully excluded (40). Plasma CRP levels show a significant difference seasonally, with higher levels in winter and spring than in summer (19). In Italy, the data of 16,422 voluntary blood donors were evaluated by month, and thrombocyte and plateletcrit values were observed to be significantly higher in fall and winter, with the peak seen especially in December and February(41).

In a study by Calton et al, a more significant increase in winter than in summer was detected in proinflammatory cytokines such as macrophage chemoattractant protein (MCP-1), TNF- $\alpha$, IL-6, IL-8, IL-10, and IL-12. CRP also increased, but there was no statistically significant difference. The higher levels of proinflammatory cytokines in winter were reported to be associated with lower levels of vitamin D in winter (42). In the current study, vitamin D levels were not evaluated, but in RA patients, the DAS 28 level was higher in winter than in summer. Vitamin D deficiency could be a factor in high proinflammatory cytokine levels in winter, but should not be considered as the only reason.

In a study by Grant et al, mortality rates were seen to be highest in December to January, and lowest in June to July. When the causes of death showing a seasonal difference were examined, acute cardiovascular events (myocardial infarction, arrhythmias, cardiac failure) and stroke were the leading causes (43).

In the current study, there was also a seasonal relationship between DAS 28, thrombocyte count and PLR in RA patients. DAS 28 was higher in winter and spring, and thrombocyte count and PLR were also higher in winter. All these values were detected to be lowest in summer. In the AS group, a seasonal relationship was only seen with RBC count, which was higher in winter and fall. More notable seasonal effects on RA may be associated with higher levels of thrombocyte levels and PLR in winter.

In conclusion, the results of the current study determined that NLR and PLR are strongly correlated with disease activity, ESR and CRP. NLR and PLR are easy, cheap, easily accessible parameters which can be used to evaluate treatment response before and after anti-TNF treatment. NLR and PLR are also age-independent parameters. This provides a superiority to ESR. NLR and PLR can be used as markers to evaluate disease activity in RA and AS patients. In addition, this study showed one more time that disease activity can change seasonally. Especially in RA patients, the disease activity and thrombocyte levels are increased in spring and winter. PLR is increased. Although the thrombocyte contribution to this event is not fully understood, it should be emphasized and further studies must be made. Although the lack of analysis of vitamin D levels was a limitation to the study, this was due to its retrospective nature. Future studies could include vitamin D analysis in terms of its effect on the immune system.

\section{References}

1. Uslu AU, Küçük A, Şahin A et al. Two new inflammatory markers associated with Disease Activity Score-28 in patients with rheumatoid arthritis: neutrophil-lymphocyte ratio and platelet-lymphocyte ratio. Int J Rheum Dis 2015; 18: 731-735.

2. Buyukkaya E, Karakas MF, Karakas E et al. Correlation of neutrophil to lymphocyte ratio with the presence and severity of metabolic syndrome. Clin Appl Thromb Hemost 2014; 20: 159-163.

3. Imtiaz F, Shafique K, Mirza SS et al. Neutrophil lymphocyte ratio as a measure of systemic inflammation in prevalent chronic diseases in Asian population. Int Arch Med 2012; 5: 2.

4. Hamminga EA, van der Lely AJ, Neumann HA et al. Chronic inflammation in psoriasis and obesity: implications for therapy. Med Hypotheses 2006; 67: 768-773.

5. Turkmen K, Erdur FM, Ozcicek F et al. Platelet-to-lymphocyte ratio better predicts inflammation than neutrophil-to-lymphocyte ratio in endstage renal disease patients. Hemodial Int 2013; 17: 391-396.

6. Ruggiero C, Metter EJ, Cherubini A et al. White blood cell countand mortality in the Baltimore Longitudinal Study of Aging. J AmColl Cardiol 2007; 49 (18): 1841-1850.

7. Rosenthal NE, Sack DA, Gillin JC et al. Seasonal affective disorder. A description of the syndrome and preliminary findings with light therapy. Arch Gen Psychiatry 1984; 41: 72-80.

8. Gallerani M, Govoni M, Mucinelli M et al. Seasonal variation in the onset of acute microcrystalline arthritis. Rheumatology 1999; 38: 10031006. 
9. Lewington S, Li LM, Sherliker $P$ et al. Seasonal variation in blood pressure and its relationship with outdoor temperature in 10 diverse regions of China: the China Kadoorie Biobank. Journal of Hypertension 2012; 30: 1383-1391.

10. Braga ALF, Zanobetti A, Schwartz J. The effect of weather on respiratory and cardiovascular deaths in 12 US cities. Environmental Health Perspectives 2002; 110: 859-863.

11. Fares A. Winter cardiovascular diseases phenomenon. N Am J Med Sci 2013; 5: 266-279.

12. Ornato JP, Peberdy MA, Chandra NC et al. Seasonal pattern of acute myocardial infarction in the National Registry of Myocardial Infarction. J Am Coll Cardiol 1996; 28: 1684-1688.

13. Marti-Soler H, Gubelmann C, Aeschbacher S, Alves L, Bobak M, Bongard $\mathbf{V}$ et al. Seasonality of cardiovascular risk factors: an analysis including over 230000 participants in 15 countries. Heart 2014; 100 : $1517-1523$.

14. De Jong S, Neeleman M, Luykx JJ, Ten Berg MJ, Strengman E, Den Breeijen HH et al. Seasonal changes in gene expression represent cell-type composition in whole blood. Human Molecular Genetics 2014; 23: $2721-2728$

15. Dopico XC, Evangelou M, Ferreira RC, Guo H, Pekalski ML, Smyth DJ et al. Widespread seasonal gene expression reveals annual differences in human immunity and physiology. Nat Commun 2015; 6: 7000.

16. Goldinger A, Shakhbazov K, Henders AK, Mcrae AF, Montgomery GW, Powell JE Seasonal Effects on Gene Expression. Plos One 2015; 10.

17. Crawford VLS, Sweeney O, Coyle PV, Halliday IM, Stout RW. The relationship between elevated fibrinogen and markers of infection: a comparison of seasonal cycles. Qjm-Monthly Journal of the Association of Physicians 2000; 93: 745-750.

18. Rudnicka AR, Rumley A, Lowe GDO, Strachan DP.Diurnal, seasonal, and blood-processing patterns in levels of circulating fibrinogen, fibrin D-dimer, C-reactive protein, tissue plasminogen activator and von Willebrand factor in a 45-year-old population. Circulation 2007; 115: 996-1003.

19. Sung KC. Seasonal variation of C-reactive protein in apparently healthy Koreans. Int J Cardiol 2006; 107: 338-342.

20. Fu H, Qin B, Hu $\mathbf{Z}$ et al. Neutrophil-and platelet-to-lymphocyte ratios are correlated with disease activity in rheumatoid arthritis. Clin Lab 2015; 61: 269-273

21. Gökmen F, Akbal A, Reşorlu H et al. Neutrophil-lymphocyte ratio connected to treatment options and inflammation markers of ankylosing spondylitis. J Clin Lab Anal 2015; 29: 294-298.

22. Coşkun BN, Öksüz MF, Ermurat $S$ et al. Neutrophil lymphocyte ratio can be a valuable marker indefining disease activity in patients who have started anti tumor necrosis factor (TNF) drugs for ankylosing spondylitis. Eur J Rheumatol 2014; 1: 101-105.

23. Boyraz I, Koç B, Boyaci A, Tutoğlu A et al. Ratio of neutrophil/lymphocyte and platelet/lymphocyte in patient with ankylosing spondylitis that are treating with anti-TNF. Int J Clin Exp Med 2014; 15: 2912-2915.

24. Mercan R, Bitik B, Tufan A et al. The association between neutrophil/ lymphocyte ratio and disease activity in rheumatoid arthritis and ankylosing spondylitis. J Clin Lab Anal 2015; doi: 10.1002/jcla.21908.

25. Zareifar S, Farahmand Far MR, Golfeshan $F$ et al. Changes in platelet count and mean platelet volume during infectious and inflammatory disease and their correlation with ESR and CRP. J Clin Lab Anal 2014; 28: 245-248.
26. Bath PM, Butterworth RJ. Platelet size measurement, physiology and vascular disease. Blood Coagul Fibrinolysis 1996; 7: 157-161

27. Kapsoritakis AN, Koukourakis MI, Sfiridaki A et al. Mean platelet volume: a useful marker of inflammatory bowel disease activity. Am J Gastroenterol 2001; 96: 776-781.

28. Kisacik B, Tufan A, Kalyoncu U et al. Mean platelet volume (MPV) as an inflammatory marker in ankylosing spondylitis and rheumatoid arthritis. Joint Bone Spine 2008; 75: 291-294.

29. Gasparyan AY, Sandoo A, Stavropoulos-Kalinoglou A et al. Mean platelet volume in patients with rheumatoid arthritis: the effect of antiTNF-alpha therapy. Rheumatol Int 2010; 30: 1125-1129.

30. Yazici S, Yazici M, Erer B et al. The platelet indices in patients with rheumatoid arthritis: mean platelet volume reflects disease activity. Platelets 2010; $21: 122-125$.

31. Savage, E. M., McCormick, D., McDonald, S., Moore, O., Stevenson, M., \& Cairns, M. P. Does rheumatoid arthritis disease activity correlate with weather conditions? Rheumatology International 2015; 35 (5): 887-890.

32. Abasolo L, Tobías A, Leon L et al. Weather conditionsmay worsen symptoms in rheumatoid arthritis patients: the possible effect of temperature. Rheumatol Clin 2013; 9 (4): 226-228.

33. Strusberg I, Mendelberg RC, Serra HA, Strusberg AM. Influence of weather conditions on rheumatic pain. J Rheumatol 2002; 29 (2): 335-338.

34. Heath CW Jr, Fortin PR. Epidemiologic studies of rheumatoid arthritis: future directions. J Rheumatol Suppl 1992; 32: 74-77.

35. Lawrence RC. Rheumatoid arthritis: classification and epidemiology, In: Klippel JH, Dieppe PA, (eds). Rheumatology. London: Mosby-Year Book, 1994

36. Akhmedov KS, Gadaev AG, Sayfiyev NY. Analysis of the course of rheumatoid arthritis depending on the climatic and geographic zones of Uzbekistan. Reumatizam 2014; 61: 13-16.

37. Ogura T, Kameda H. Autoimmune diseases and seasonal variations. Nihon Rinsho Meneki Gakkai Kaishi 2014; 37: 25-32.

38. Grazio S, Jalic Z, Jalic I, Vlak T. The mode of onset of rheumatoid arhritis and seasonal variations. Reumatizam 1995; 42: 1-6.

39. Patberg WR, Rasker JJ. Weather effects in rheumatoid arthritis: from controversy to consensus. A review. J Rheumatol 2004; 31: 1327-1334.

40. Cay HS, Sezer I, Firat MZ, Kacar C. Which is the dominant perception of rheumatic pain: meteorology or psychology?Rheumatol Int 2011; 31: 377-385.

41. Gallerani M, Reverberi R, Salmi R, Smolensky MH, Manfredini R. Seasonal variation of platelets in a cohort of Italian blood donors: a preliminary report. Eur J Med Res 2013; 18: 31.

42. Calton EK, Keane KN, Raizel R, Rowlands J, Soares MJ, Newsholme $\mathbf{P}$. Winter to summer change in vitamin D status reduces systemic inflammation and bioenergetic activity of human peripheral blood mononuclear cells. Redox Biol 2017; 12: 814-820.

43. Grant WB, Bhattoa HP, Boucher BJ. Seasonal variations of U.S. mortality rates: Roles of solar ultraviolet-B doses, vitamin $\mathrm{D}$, gene expression, and infections. J Steroid Biochem Mol Biol 2017.

Received April 9, 2019. Accepted May 14, 2019. 